\title{
REESCRITURA LITERARIA: MALINCHE BAJO LA MIRADA DE LOS ESTUDIOS POSTCOLONIALES
}

\author{
Walquíria Rodrigues Pereira \\ Mestranda em Letras Neolatinas (Literaturas Hispânicas) pela Universidade Federal do Rio \\ de Janeiro (UFRJ) \\ walquiria_rodrigues2007@hotmail.com \\ Ximena Antonia Díaz Merino \\ Doutora em Letras Neolatinas (Literaturas Hispânicas) pela Universidade Federal do Rio de \\ Janeiro (UFRJ) \\ Professora Adjunta da Universidade Federal Rural do Rio de Janeiro (UFRRJ) \\ ximenadm2@gmail.com
}

\section{RESUMO}

A proposta desse estudo é revelar outra perspectiva sobre a figura de Malinche, reflexões que serão realizadas sob a luz dos estudos pós-coloniais. As análises serão realizadas a partir do romance Malinche (2006), de Laura Esquivel e do ensaio El laberinto de la soledad (1950), de Octavio Paz. Mediante a uma leitura questionadora e reflexiva serão observadas as diferentes perspectivas dos dois autores na construção da imagem do símbolo mexicano Malinche, a visão da mulher refém da violência colonizadora contra a visão da mulher que traiu seu povo. Através da reescrita da figura de Malinche encontramos a voz do excluído que no meio da colonização busca manter sua identidade, sua cultura e os seus valores, um novo enfoque, que permite adotar estratégias de resistência como meio de sobrevivência em oposição ao discurso dominante. As observações serão norteadas pelos estudos críticos de: Homi K. Bhabha (1998), Thomas Bonnici (2005, 2009), Walter Mignolo (1996, 2008) e Maria Emília Granduque José (2016).

Palavras-chave: Literatura; reescrita; estudos pós-coloniais; Malinche.

\section{RESUMEN}

La propuesta de este estudio es revelar otra perspectiva sobre la figura de Malinche, reflexiones que serán realizadas a la luz de los estudios postcoloniales. As análisis serán realizadas a partir de la novela Malinche (2006), de Laura Esquivel y del ensayo EI laberinto de la soledad (1950), de Octavio Paz. Por medio de una lectura cuestionadora y reflexiva serán observadas las diferentes perspectivas de los dos autores en la construcción de la imagen del símbolo mexicano Malinche, la visión de la mujer rehén de la violencia colonizadora en contrapunto con la visión de la mujer que traicionó a su pueblo. A través de la reescritura de la figura Malinche, encontramos la voz del excluido, que en medio de la colonización busca mantener su identidad, su cultura y sus valores, un nuevo enfoque que permite adoptar estrategias de resistencia como medio de supervivencia en oposición al discurso dominante. Las observaciones se guiarán por los estudios críticos de: Homi K. Bhabha (1998), Thomas Bonnici (2005, 2009), Walter Mignolo (1996, 2008) e Maria Emília Granduque José (2016).

Palabras clave: Literatura; reescritura; estudios postcoloniales; Malinche. 


\section{Introducción}

Este estudio es fruto de un trabajo de investigación de iniciación científica, financiando por el CNPq, que busca ante una lectura cuestionadora a la luz de los estudios postcoloniales, observar la construcción de la figura del mito mexicano Malinche bajo la óptica de Octavio Paz, a través del ensayo El laberinto de la soledad (1950) y de Laura Esquivel, a través de la novela Malinche (2006).

En estas dos perspectivas, que se contraponen, podemos percibir cuanto la historia es influenciada cuando sólo es contada por la visión del lado hegemónico, silenciando la voz del subyugado, ya que, a través de la reescritura propuesta por los estudios postcoloniales encontramos la voz del excluido, que en medio de la opresión colonizadora busca preservar su identidad, su cultura y sus valores, adoptando estrategias de resistencia como una forma de oposición y supervivencia al discurso dominante.

Podemos reflexionar también sobre los impactos de la colonización en la historia de la civilización mexicana como los estudios postcoloniales nos orientan para comprender la identidad del sujeto colonizado y a partir de un análisis literario sobre la historia considerada como la oficial, pautado en esos estudios, podemos percibir la resistencia contra el control colonial.

\section{Los estudios postcoloniales}

Antes de analizar la figura histórica de la indígena Malinalli, dentro de la novela Malinche (2006), de Laura Esquivel y del ensayo El laberinto de la soledad (1950), de 
Octavio Paz, a partir de los estudios postcoloniales, es necesario aclarar algunos aspectos importantes de estos estudios para una mejor comprensión del trabajo. Proponemos aclaraciones sobre los términos postcolonialismo, reescritura, relectura y resistencia a partir de los escritos de Bonnici (2009). Y aún a partir de las perspectivas de otros autores sobre el tema como Izvetan Todorov (1982), Carlos Fuentes (1992) y Homi K. Bhabha (1998).

La propuesta de los estudios postcoloniales es analizar las huellas dejadas por el colonialismo, como la invasión de América que devastó muchos pueblos e desplegó una cultura europea como paradigma, puesto que el postcolonialismo "refere-se a toda a cultura influenciada pelo processo imperial a partir do momento da colonização até a contemporaneidade." (BONNICI, 2009, p. 22). Es decir, son las marcas sociales, culturales y lingüísticas que forman parte de la historia, influenciando en la construcción de la identidad de una sociedad que ha sido colonizada. Estas marcas se dan debido al silenciamiento diacrónico de una cultura / pueblo (dominado) en relación a otro (dominante) y también al encuentro de culturas, resultando en hibridismo, mezcla de culturas y prácticas sociales entre colonizador y colonizado.

De acuerdo con Thomas Bonnici (2009, p. 26) de la tensión entre el sujeto colonizado con el poder colonizador surge la Literatura Postcolonial, ya que ésta es basada en el poder colonizador. A partir de esa experiencia el colonizado puede contar su historia, asumiendo el protagonismo antes dejado de lado, de esa manera, a través de la Literatura postcolonial otra mirada nos es revelada, diferente de la historia oficial. Es una forma de proporcionar voz a quien no tenía y desmitificar el concepto del sujeto "tabula rasa", una hoja en blanco a ser llenada. 
La reflexión postcolonial propone una mirada crítica a partir de estrategias como la relectura de obras literarias "uma maneira de ler os textos literários para revelar suas implicações no processo colonial." (BONNICI, 2009, p. 40), un modo analítico de leer los textos cuestionando las implicaciones surgidas en el proceso colonial, de esa manera el autor reescribe esos textos pues, "se aproveita de lacunas, silêncios, alegorias, ironias $e$ metáforas do texto canônico." (BONNICl, 2009, p. 40), creando otro texto con valor e intencionalidad completamente diferente del primero, proporcionando un nuevo enfoque.

Las estrategias de relectura y reescritura configuran resistencia y supervivencia, ya que, "[...] a literatura pós-colonial, informada pela resistência, usa a linguagem imperial para rechaçar a ideologia dominante e as estratégias usadas para descartá-la como periférica e derivativa." (BONNICl, 2009, p. 46), haciendo que el uso de la lengua de la escritura dominante tenga por objetivo que su voz y / o mensaje sean oídos, y así, someter las imposiciones de los colonizadores mediante la reproducción de sus actitudes, sin dejar su creencia o su cultura de lado. Este ser oprimido y subalternizado (en el sentido de subyugado y menospreciado por la ideología hegemónica) puede ganar voz a través de estrategias de resistencia como la mímica, que al oponerse a la autoridad colonial la amenaza, puesto que

[...] a mímica emerge como a representação de uma diferença que é ela mesma um processo de recusa. A mímica e, assim, o signo de uma articulação dupla, uma estratégia complexa de reforma, regulação e disciplina que se 'apropria' do Outro ao visualizar o poder (BHABHA, 1998, p. 130). 
El papel de la resistencia en la literatura poscolonial consiste en oponerse a la sumisión impuesta por los colonizadores a través del contra-discurso, de manera que por medio de la mímica los colonizados "enmascaran" su cultura, y utilizan la cultura, la lengua y la religión impuesta apenas como forma de sobrevivencia, pues están frente a la dominación, pero detrás de aquella imposición ellos siguen cultivando sus costumbres y tradiciones culturales. El nativo era visto como objeto, como un ser subalterno, mudo y sin voz, como enfatizado por Bonnici e Zolin (2009, p. 265): “O colonizador, seja espanhol, português, inglês, se impõe como poderoso, civilizado, culto, forte, versado na ciência e na literatura. Por outro lado, o colonizado é descrito constantemente como sem roupa, sem religião, sem lar, sem tecnologia, ou seja, em nível bestial."

El individuo colonizado, el indígena, en la historia considerada oficial, es citado como desprovisto de cualquier conocimiento o cultura por no encajarse en los paradigmas propuestos por la cultura europea, por la hegemonía. Toda asociación hecha a él estaba relacionada con la inferioridad. Esta descripción nos proporciona la visión del colonizador ante el colonizado, para él, el colonizado será siempre inferior, representado con un ser periférico y subalterno, términos que para Mignolo presentan una semejanza.

O sentido de 'periférico' é analógico ao sentido de 'subalterno', se concebermos que o termo se refere a 'culturas' e línguas e não apenas a classes sociais e comunidades - isto é, tudo que se situa num espaço relacional será colocado 'numa posição inferior' (MIGNOLO, 2003, p. 270).

El sentido de subalternidad en el medio postcolonial puede ser relacionado aún a la mujer, ya que, "em sociedades pós-coloniais, a mulher é duplamente subalterna: ela é o objeto da historiografia colonialista e da construção do gênero" (BONNICI; ZOLIN, 2009, p. 
266), así podemos ver que los estudios postcoloniales y el feminismo se relacionan, pues ambos discursos apuntan a la integración de la mujer, antes marginada de la sociedad. Si reflexionamos sobre la historia y la representación de la mujer, encontraremos diversos relatos relacionados a la esclavitud y la sexualidad. Los personajes femeninos que se presentan en la historia muchas veces fueron explotados por ella de acuerdo con los relatos históricos "a mulher sempre foi relegada ao serviço do homem, ao silencio, a dupla escravidão, à prostituição ou a objeto sexual, na literatura, muitos são as romances que representam, através de suas personagens femininas, essa situação" (BONNICl; ZOLIN, 2009, p. 266). De acuerdo con el razonamiento descolonial presentado analizaremos la figura de la mujer e indígena Malinche y su representación histórica.

\section{2. ¿Quién fue Malinche?}

Ciertamente, todavía hay muchas dudas en cuanto a la precisión de su fecha de nacimiento, pero se sabe que a pesar de su nombre resonar en la historia de México, Mallinalli, Malinche, o Doña Marina murió aún joven.

Malinche fue una indígena nacida de la región del golfo de México, que durante el período de conquista de ese territorio fue usada por los conquistadores como instrumento de comunicación, pues poseía una gran habilidad lingüística y facilidad en aprender idiomas. Era natural de Painalla y fue vendida por su propia madre a los indios de Xicalango después de quedarse viuda y contraer nuevo matrimonio, pues no quería que un nuevo heredero dividiera al cacicado. Más tarde, ya en la adolescencia, fue dada a la tropa de Cortés. Sobre ese episodio Bernal Díaz de Castillo relata: 
[...] aquela índia e senhora que ali nos deram [...] era grande cacica, filha de grandes caciques e senhora de vassalos; e bem se parecia em sua pessoa; a qual direi adiante como e de outras mulheres que não me lembro bem de todos os nomes (DÍAZ DEL CASTILLO, 1999, p. 59 apud JOSÉ, 2016, p. 97).

Podemos percibir que las mujeres eran tratadas como mercancía, otras indígenas no tuvieron sus nombres destacados por no poseer las habilidades lingüísticas de Malinche, probablemente si ella tampoco poseyera tales habilidades jamás habría entrado a la historia y acabaría como las miles de mujeres indígenas que eran vendidas y esclavizadas.

En cuanto a la "posesión" de Cortés, Malinche fue bautizada de acuerdo con el catolicismo siendo conocida por Doña Marina, es usada por él como instrumento lingüístico en la conquista y también como objeto sexual. Cuando su papel deja de ser crucial, ella es "dada" por Cortés en matrimonio a uno de sus oficiales.

\section{Las representaciones sobre la mujer indígena}

Las diversas representaciones escritas e iconográficas atribuidas al mito Malinche influenciaron en la construcción de la identidad del pueblo mexicano a lo largo de la historia de México, pues algunos tratan de repeler la descendencia de una "madre chingada", violada y adepta al extranjero y otros la analizan como rehén de un régimen patriarcal que se transformó en un "chivo expiatorio".

De acuerdo con las consideraciones de Dominique Vieira Coelho SANTOS (2011, p. 27), la palabra representación es "de origen latina, oriunda del vocablo repraesentare que significa "hacer presente" o "presentar de nuevo". Santos (2011) destaca que el propio 
sujeto puede ser construido a través de una representación y que una representación puede estar sometida a otra representación, es decir, ella "[...] deixa de ser entendida então como algo mimético, cópia pura e simples, para ser entendida como substituição, ou seja, a representação não é o real." (SANTOS, 2011, p. 42-43). De esta forma, una representación puede ser considerada un ámbito de lo real, proporcionando una correlación donde real y representación necesitan uno del otro para existir, y explica que

O pressuposto do qual partem os autores que trabalham com as representações sociais é de que os fenômenos humanos podem ser conhecidos e explicados a partir de uma perspectiva coletiva, mas sem ignorar o indivíduo. Trata-se de uma forma de conhecimento que tenta construir uma realidade comum a um conjunto social (SANTOS, 2011, p. 32).

Santos (2011) argumenta con bases en los estudios de Émile Durkheim, sobre las representaciones sociales, dice que los actos, las ocurrencias humanas son, normalmente, justificadas por una perspectiva colectiva, pero sin excluir al individuo, es decir, es un entendimiento que busca producir una realidad general común a un conjunto social y añade que

o conceito de representação coletiva foi introduzido em 1898 pelo sociólogo francês. Com este conceito, Durkheim pretendia explicar fenômenos como a religião, por exemplo, que, segundo ele, deveria ser pesquisada a partir de investigações que tivessem por objetivo o coletivo. Émile Durkheim, ao propor esta divisão, se fundamentava na concepção de que as regras que comandam a vida individual são distintas das que comandam a vida coletiva (SANTOS, 2011, p. 32).

El contexto histórico debe tenerse en cuenta en la configuración de una determinada representación y ésta puede verse reflejada en la identidad de una nación, 
como podemos observar en la figura de Malinche y de los mexicanos. Pues, frente a un movimiento de exaltación de la nacionalidad, "la mexicanidad", y del intento de alejamiento de las influencias extranjeras, se atribuyó a esa mujer mexicana indígena y esclava la imagen de traidora de la nación, característica que resuena hasta los días actuales. La óptica del postcolonialismo permite que los escritores, ante una visión cuestionadora, relean y reescriban la historia de Malintzin. Los cuestionamientos que giran en torno a la imagen de Malinche serán observados en las pinturas que destacaremos a continuación, confrontando las representaciones de esa indígena presentadas por Octavio Paz y Laura Esquivel.

\section{La Malinche de Octavio Paz}

Octavio Paz abre el capítulo "Hijos de la Malinche", parte constitutiva del ensayo El laberinto de la soledad, defendiendo la idea de que los mexicanos, así como los orientales, son un pueblo que no acepta manifestaciones externas, es decir, extranjerismo vinculados a sus tradiciones. Paz reflexiona sobre las raíces históricas de su país, sobre los "fantasmas" que rondan el origen de México y de la figura femenina que representa a la progenitora de la nación. Paz, evoca a los mexicanos a alejarse de toda influencia extranjera, el grito de independencia: "iViva México, hijos de la chingada!", la figura de madre "chingada" y sus descendientes son asociados por el autor a los enemigos, a los malos mexicanos receptivos al extranjero, como podemos observar en el fragmento abajo: 
[...] ¿Y quiénes son los demás? Los demás son 'hijos de la chingada': los extranjeros, los malos mexicanos, nuestros enemigos, nuestros rivales. (...) La chingada es la madre que ha sufrido, metafórica o realmente, la acción corrosiva e infamante explícita en el verbo que le da nombre (PAZ, 1984, p. 35).

Para el autor mexicano, el propio sentido contenido en el verbo "chingar" está relacionado al fracaso, a la humillación, al maltrato, él afirma que es un verbo masculino, que denota violencia y pasividad. Ser hijo de esa "chingada" representa todo lo que es malo. Esta madre "chingada" de la nación, de los malos mexicanos y fascinada con el extranjero es Malinche, pues de acuerdo con Paz, se ofreció voluntariamente al invasor Cortés traicionando, en el proceso sangriento de la invasión española, a su pueblo al transformarse en su amante. Como si el hecho de haber sido vendida, ofrecida y tratada como un objeto de posesión y de triunfo en la conquista no influenciara su vida.

El símbolo de la entrega es doña Malinche, la amante de Cortés. Es verdad que ella se da voluntariamente al Conquistador, pero, éste, apenas deja de serle útil, la olvida. Doña Marina se ha convertido en una figura que representa a las indias, fascinadas, violadas o seducidas por los españoles (PAZ, 1984, p. 35).

Octavio Paz contrapone la imagen de Malinche, "la madre chingada" que no ofreció resistencia al dominio español, con la imagen inmaculada de la Virgen de Guadalupe, que para él es la encarnación de la representación femenina. Así, por el hecho de que los mexicanos no puedan perdonar esa "traición", ellos necesitan distanciarse de las raíces indígenas y españolas, creando un sentimiento de orfandad, necesitando reinventarse para romper sus orígenes con el pasado. Paz afirma que Malinche es la Eva mexicana, la mujer que introduce el pecado, como representada en la obra de José Clemente Orozco: 
Figura 1 - José Clemente Orozco. Cortés Y Malinche, 1926.

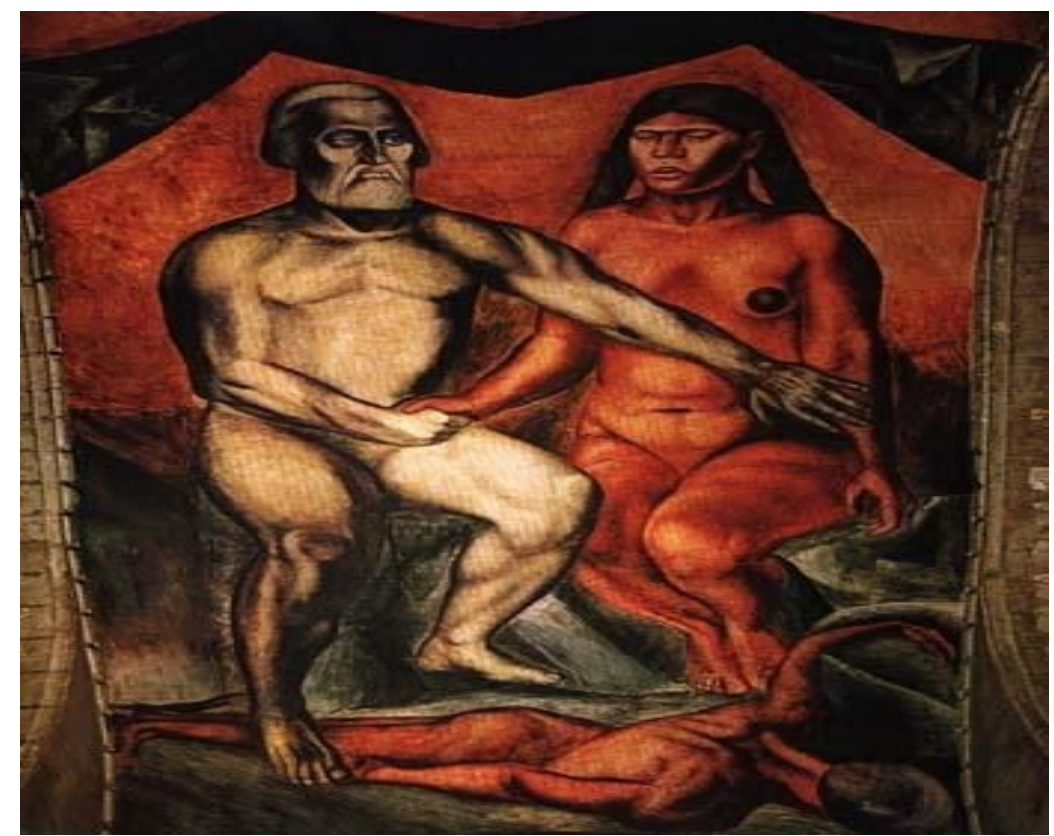

Fonte: $<$ http://www.lospoliticosveracruz.com.mx/del-dolor-de-la-malinche-y-cortes/>.

En la pintura de Orozco, Malinche es representada principalmente como mujer sumisa, pasiva y amante de Cortés, sin ofrecer resistencia, en posición de compañerismo al conquistador a través de las manos entrelazadas. Sus ojos están cerrados, como si la indígena estuviera poniendo su confianza ciegamente en Cortés. Él parece contener a la indígena que pasivamente queda impedida de ayudar al cuerpo caído. La idea expuesta es de realzar la naturaleza femenina y sexual de Malinche. La verdadera Eva mexicana, como retrata Paz en su ensayo, que a través de los atributos femeninos es capaz de persuadir e influenciar la toma de decisiones. La relación de carnalidad pagana da origen al hijo mestizo, hijo que está en el suelo, pisoteado, derribado igual a los pueblos que sufrieron con la conquista. Su representación remite a la amante sumisa y cómplice y no a su papel de intérprete. 
Figura 2 - Antonio Ruíz. El sueño de la Malinche, 1939

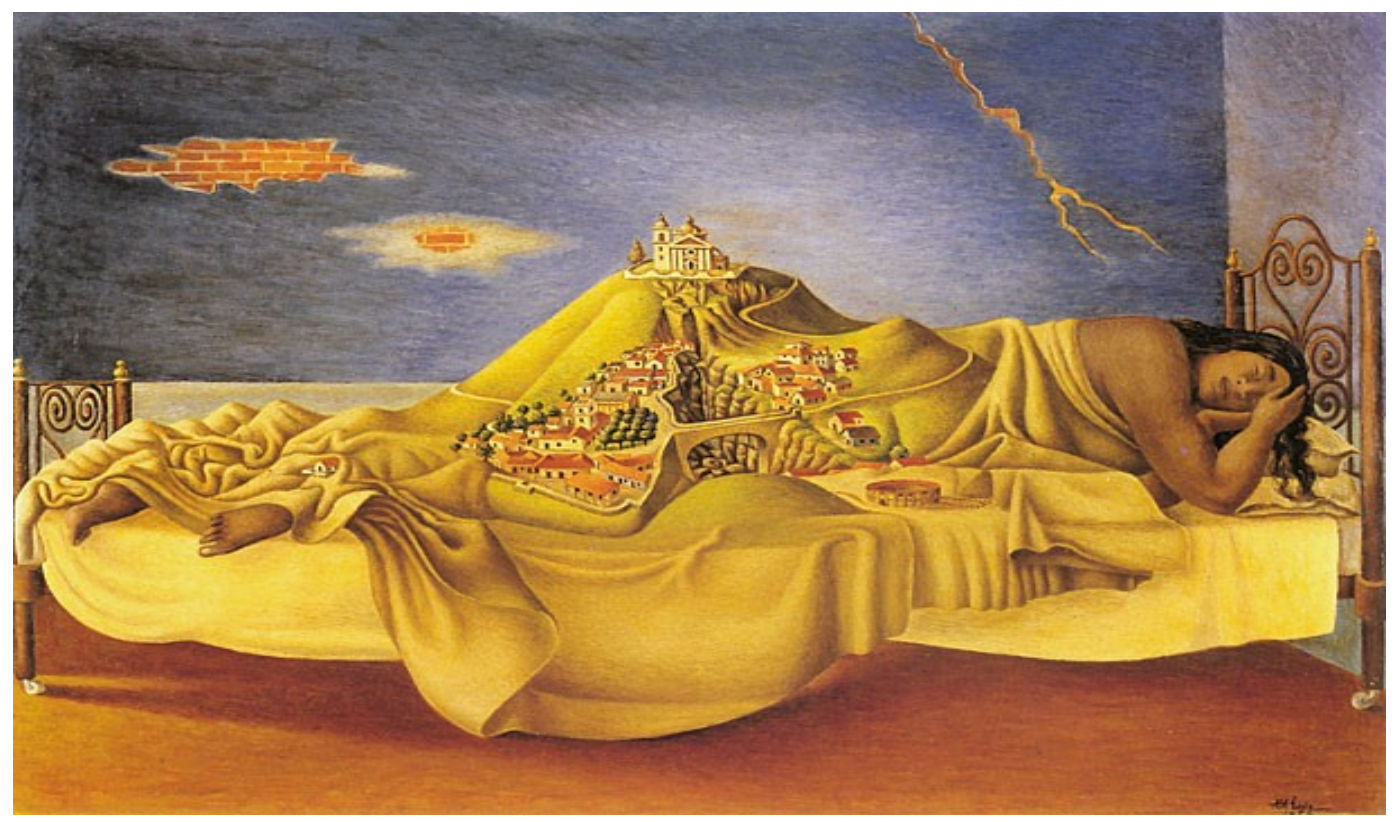

Fonte: <http://comopamdaboca.blogspot.com.br/2011_08_01_archive.html>.

En la pintura de Ruíz podemos observar que toda la construcción de la ciudad de México se encuentra sobre las curvas del cuerpo de la indígena. Como si todos los acontecimientos de la colonización hubieran ocurrido por la naturaleza sexual que envolvió su convivencia con el conquistador. Malinche parece dormir tranquilamente, como si el contenido sexual que envolvió su relación con Cortés dando origen a la nación no hubiera sido violento y sí deseado y consensual. Una vez más su representación está relacionada a la sexualidad y al papel de amante que le fue asignado. Inconsciente, con un sueño tranquilo, ella parece comprender que su sexualidad es el punto principal para la fundación de la nación. Una mujer representada sólo por la relación sexual que le fue impuesta y no por sus habilidades y actitudes, representación que coincide con la perspectiva de Paz. 
Figura 3: Jesús Helguera, Cortés y La Malinche

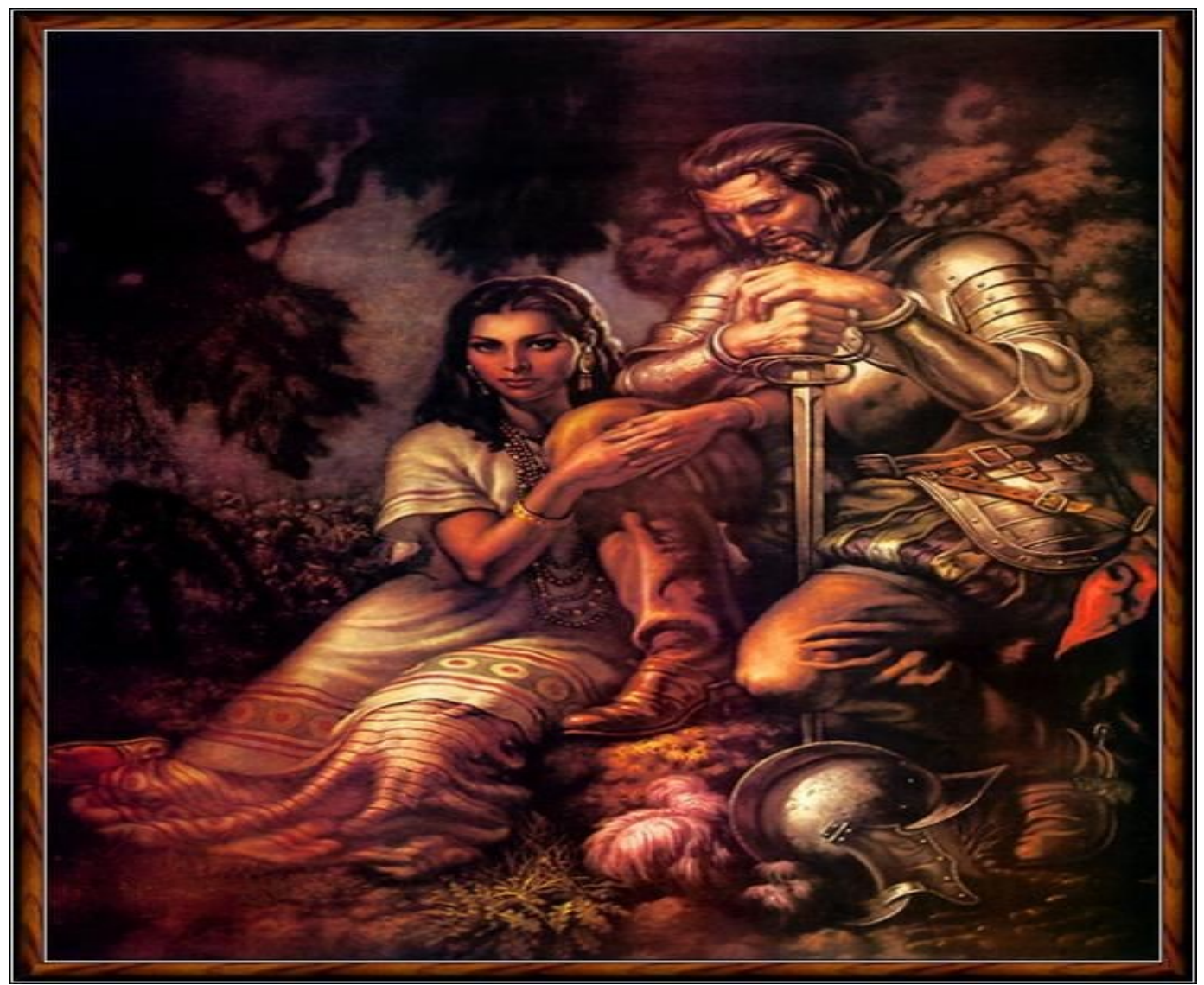

Fonte: <https://www.pinterest.pt/pin/211950726191676289/?autologin=true>.

En la pintura de Helguera percibimos el aire novelado de las historias de caballería.

Cortés es representado como un tipo de caballero, héroe y valiente empuñando su espada y Malinche es su musa. Nuevamente la indígena tiene su imagen representada por su relación sexual con el conquistador, como señalada por Paz. Ella es dibujada como una mujer bella y misteriosa. Su mirada parece provocadora y su complicidad con el español es constatada por medio de sus brazos entrelazados a las rodillas de Cortés, mostrando la asociación existente entre los dos. Ellos parecen tener la conexión y la "química" de una pareja descrita en las historias y películas románticas.

\section{La Malinche de Laura Esquivel}


Laura Esquivel, a partir de la reescritura histórica de Malinalli, propone en su novela una nueva mirada sobre la imagen del mito mexicano, proporcionando voz a la figura considerada traidora de la nación. Ella nos presenta una Malinalli humana, llena de sueños y cuestionamientos y reflexiona sobre su papel, si fue escogido o impuesto a ella, rescatando la cultura indígena, que es bien descrita y valorada en la novela. En la novela de Esquivel acompañamos a Malinalli desde el día turbulento de su nacimiento, su vida llena de incertidumbres y aspiraciones por un futuro mejor hasta su muerte precoz. Encontramos una mujer que anhelaba que Cortés pusiera fin a los sacrificios humanos, como en el relato abajo:

\footnotetext{
Ya no se sentía segura con nadie. Si en un principio se había sentido feliz de haber sido elegida como "la lengua» y de haber recibido la promesa de que se le daría la libertad a cambio de su trabajo como intérprete, ahora ya nada le garantizaba su anhelada libertad. (...) ¿Qué le garantizaba que su vida sería respetada por esos hombres que no respetaban nada? (ESQUIVEL, 2006, p. 102).
}

La mujer indígena que ansiaba por su libertad, que tuvo no sólo una función impuesta debido a sus habilidades lingüísticas, sino también, una nueva identidad, un nuevo nombre, una nueva cultura, una nueva religión y una relación que le fue impuesta. La Malinche de Laura Esquivel es Malinalli, tiene su identidad indígena respetada, valorada. Ella vivía en armonía con la naturaleza y con sus dioses, buscaba su libertad y su pedazo de tierra para plantar maíz. Quería ver su pueblo feliz y libre de la violencia, luchaba consigo misma, pues no compartía de los ideales de los conquistadores, sentía voluntad de exponer los españoles a los líderes indígenas, pero sabía que debido al cargo de intérprete que le fue atribuido podría ser muerta 
[...] Malinalli podía impedir que esto sucediera, podía proclamar que los españoles no eran enviados de Quetzalcóatl y en un segundo serían destruidos..., pero ella sería asesinada junto a ellos, y no quería morir como esclava. Tenía muchos deseos de vivir en libertad, de dejar de pasar de mano en mano, de llevar una vida errante (ESQUIVEL, 2006, p. 74).

Esquivel rompe la idea de entrega, amante pasiva y expone a una mujer indígena repleta de miedos ante la violencia psicológica, física y sexual vivenciada. La autora denuncia la violencia sufrida por Malinalli, así como sucedió con otras indígenas que no entraron en la historia, y muestra que la representación de la relación sexual voluntaria entre Malinche y Cortés presenta un contraste con la defendida por Paz.

Besó su boca, sus senos, su vientre, sus muslos, su centro, para satisfacer una voluntad tan furiosamente ambiciosa que casi la partió en dos, la lastimó, la rasgó. Al terminar, Malinalli no quiso mirarlo a los ojos, salió del palacio y se lavó en uno de los canales (ESQUIVEL, 2006, p. 128).

Malinalli no es descrita como una traidora o una mujer que se entregó al extranjero, al conquistador, sino como una mujer colonizada que no tenía opción, que fue vendida, dada de regalo y que sobrevivió solamente porque su posición le aseguraba eso. No quería ver a su pueblo diezmado, por eso, vivía en conflicto porque tampoco quería perder su vida en medio de tanta masacre. Las pinturas siguientes representan a Malinalli de acuerdo con a la reescritura historica de Laura Esquivel. 
Figura 4 - Códex Mendoza

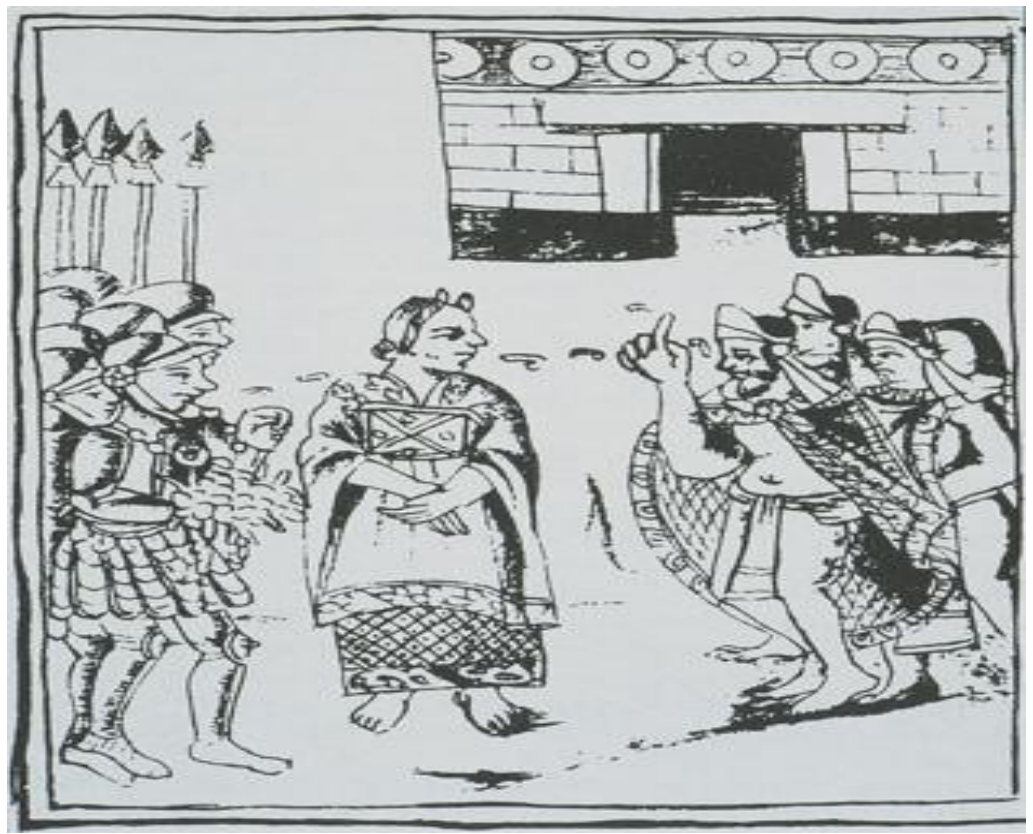

Fonte: <http://www.proppi.uff.br/ciberlegenda/iconografias-da-malinche-e-sor-juana>.

El Códex Mendoza (1540) es una representación hecha por escribas aztecas en un momento posterior a la conquista de México. En él vemos a la indígena Malinalli, la descrita por Esquivel, y no la traidora Malinche, ahora es representada actuando como interprete y aparece vestida con ropas indígenas en medio de los nativos y de los conquistadores. El Códex expone atributos relacionados con las habilidades comunicativas, Malinalli está en medio de las dos culturas, en medio de las dos lenguas. En el centro de la comunicación, recibe y transmite las palabras de un idioma al otro. Su boca funciona como instrumento capaz de contener y transportar una lengua a otra. Aquí no aparece del lado de los españoles, sino como una agente de la comunicación. 
Figura 5 - Obra y autor desconocido

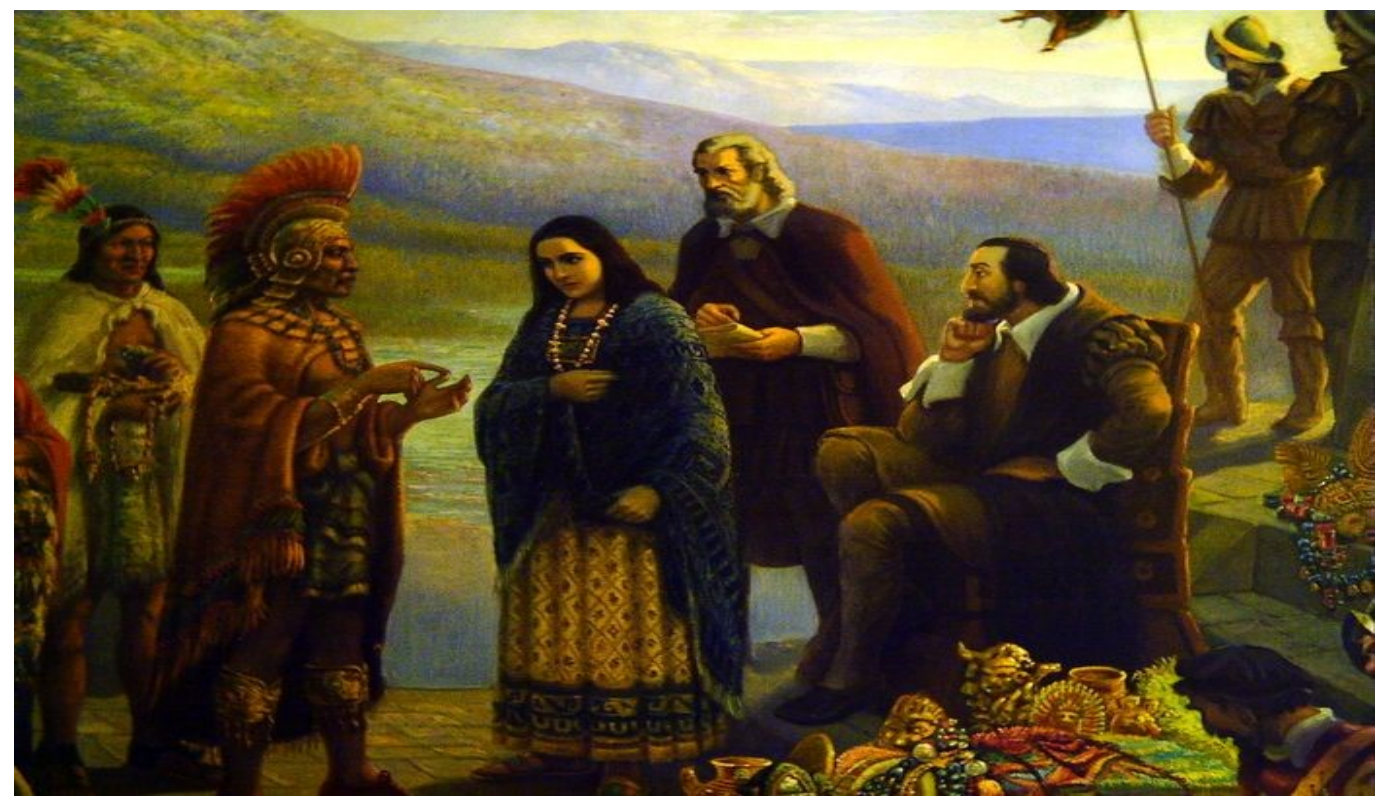

Fonte: <http://www.esnoticiaveracruz.com/mitos-y-otros-cuentos-el-traductor-de-la-malinche/.

En la pintura anterior observamos a Malinalli ejecutando el papel de intérprete que le fue impuesto. Notamos que está en el medio, entre los españoles y los indígenas. Su ropa es simple y su representación está lejos del estereotipo sexual de amante. Ella se presenta humilde, en la posición de eslabón principal en la comunicación y representa el "encuentro de las culturas". Podemos relacionar esa imagen también al conflicto interno relatado por Esquivel, pues se encontraba dividida entre las dos culturas. Dividida entre la vida recorrida e impuesta y una vida futura, soñada con la libertad deseada. Malinalli es representada por su papel histórico, sus habilidades comunicativas, se describe de forma independiente, el enfoque es su posición y habilidad, haciéndonos pensar, de acuerdo con Labriola (2010), que probablemente desempeñó el papel de primera traductora simultánea y diplomática de la historia latinoamericana. 
Figura 6 - Diego Rivera. Detalhe de Cortés e Malinche no Mural México colonial até 1930

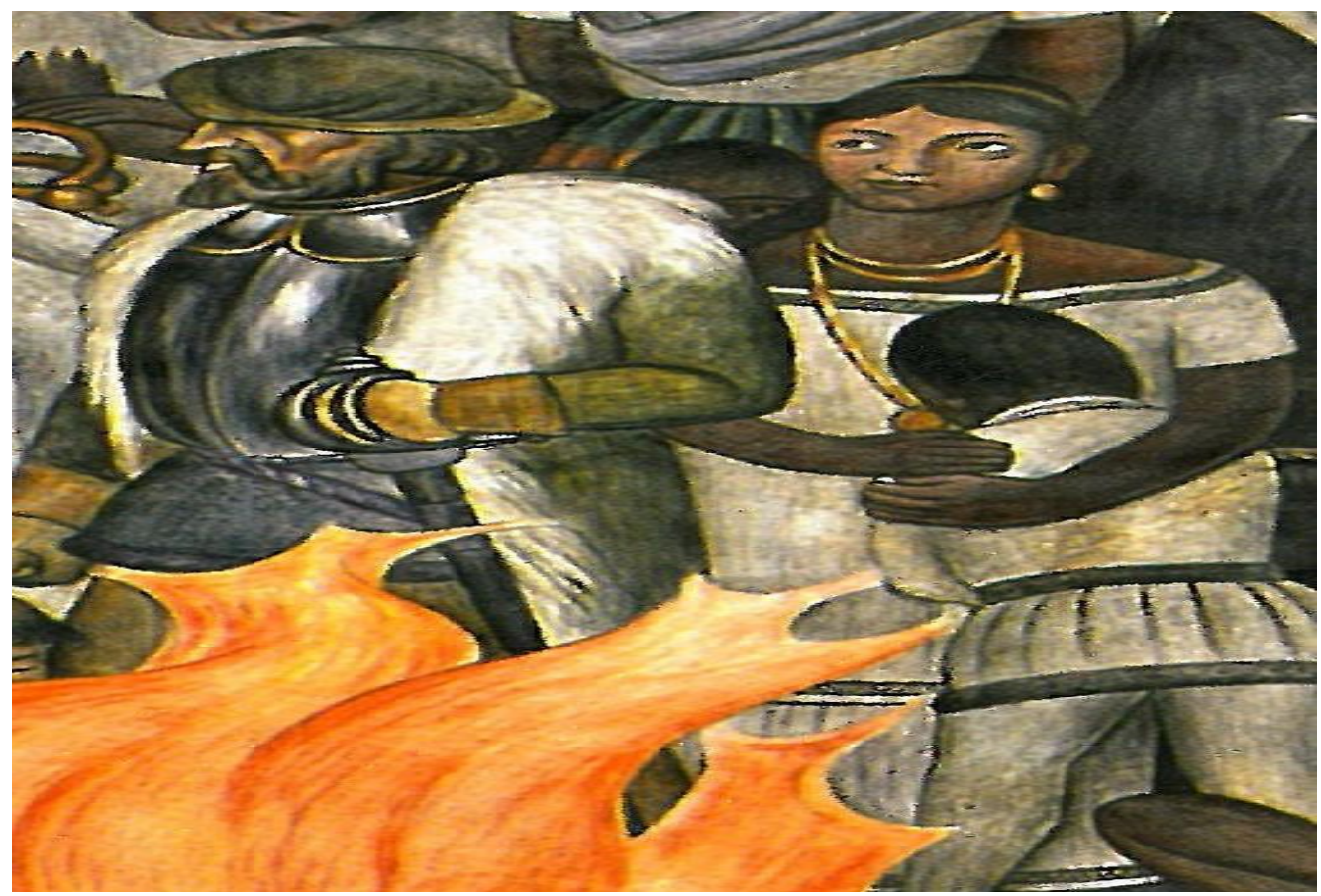

Fonte:

<http://repositorio.ufes.br/bitstream/10/3517/1/tese_5859_jorcy\%20disserta\%C3\%A7\%C3\%A3o.pdf>.

En el mural colonial de Rivera encontramos algunas representaciones sobre determinados acontecimientos históricos de México, como las marcas de la violencia de la colonización de los españoles sobre los indígenas; las atrocidades y la violencia sexual sufrida por las mujeres indígenas en la época. El detalle del mural de Rivera presentado arrida está compuesto por la representación de Cortés, Malinche y su hijo Martín, simbolizando el primer mestizo. Ante ese contexto violento el hijo esconde su rostro en la figura materna. Su cara no se muestra, como la de Cortés, que está cubierta por un sombrero. Cortés parece dirigirse hacia donde ocurre la explotación del trabajo indígena y da la espalda a Malinalli y a su hijo. Del trío, la mujer indígena es la única que está de ojos abiertos, que parecen mirar más allá de aquella situación violenta. Sus ojos abiertos nos permiten interpretar que ella no es pasiva, sino que está viendo la angustia vivida por los nativos. Ella no está "ciega" ante el conquistador que pisa al mestizo derrumbado, como 
vimos en la pintura de Orozco. Ella ve lo que pasa y teme por su hijo, viviendo un conflicto interno, como narra Esquivel. Ella abraza a su hijo, al mestizo, a la raza indígena con la intención de protegerla. Al mismo tiempo que es oprimida por Córtes ella es una madre celosa que se aferra a la figura del hijo viendo una esperanza de continuación de su raza.

\section{Consideraciones finales}

Después de las reflexiones y los análisis desarrollados podemos concluir que Octavio Paz procuró distanciarse de las raíces indígenas y españolas para romper la conexión con un pasado atado a la simbología de entrega y sumisión representada por Malinche. Mientras que Laura Esquivel rescata y exalta las raíces indígenas de Malinalli, mostrando que los elementos de la cultura originaria están consolidados no sólo en la identidad de esa figura histórica, sino que también están presentes en la historia del pueblo mexicano.

Se percibe que la reescritura de Esquivel sobre Malinche nos posibilita oír la voz antes silenciada por la historia destacando que el sujeto colonial no se entregaba voluntariamente, aunque no hubiera la violencia física, se resistía al control colonial a través de estrategias de resistencia como la mímica (BHABHA, 1998), ya que reproducir las normas dominantes impuestas no significa estar de acuerdo o rendido a la situación, sino que representa una forma de supervivencia, pues su cultura seguiría siendo preservada, lejos de los ojos colonizadores. Malinalli quería salvarse, protegerse y por medio de la lengua lo hizo mientras pudo.

Cuanto al papel de intérprete atribuido a Malinalli, fue apenas visando el interés por la conquista, si no fuera Malinalli, ciertamente otro nativo que poseyera las mismas 
habilidades sería víctima de esa triste trama. En nombre de la codicia, del poder y de la dominación, cada paso era planeado por los conquistadores. Malinalli soñaba con la libertad, pero tuvo su destino trazado y decidido por otros. En las crónicas Malinche es siempre mencionada como "La lengua" de Cortés, pero los españoles valorizaban la lengua y no a la mujer indígena, y así como Aguilar fue sustituido debido a las habilidades de Malinche sobrepasar las suyas, ella también podría ser fácilmente sustituida, tanto que fue descartada cuando su función dejó de ser conveniente a la conquista de México. Los relatos de las crónicas que la hicieron "bien vista", como pieza clave en la conquista por los españoles, fueron los mismos que la hicieron "mal vista", como traidora ante los mexicanos. La novela de Laura Esquivel, a través de los estudios postcoloniales, nos hace cuestionar por qué se atribuye el adjetivo de traidora a quien no tenía opción, que fue usada como herramienta, y no a quien utilizó la herramienta.

\section{Referencias bibliográficas}

BHABHA, Homi K. Da mímica e do homem: a ambivalência do discurso colonial. In: O local da cultura. Belo Horizonte: Editora UFMG, 1998. p. 129-138.

BONNICI, Thomas (org.). Resistência e intervenção nas literaturas pós-coloniais. Maringá: EDUEM, 2009.

BONNICI, Thomas e ZOLIN, Lúcia Osana (orgs.). Teorias e críticas pós-colonialistas. In: Teoria literária: abordagens históricas e tendências contemporâneas. 3. ed. Maringá, PR: EDUEM, 2009. p. 257-283.

ESQUIVEL, Laura. Malinche. México, D. F.: Col. Granjas Esmeralda, 2006.

JOSÉ, Maria Emília Granduque. A Malinche dos cronistas. Curitiba: Prismas, 2016.

MIGNOLO, Walter D. Os estudos são subalternos são pós-modernos ou pós-coloniais? As políticas e sensibilidades dos lugares geoistóricos. In: Histórias locais / Projetos globais: 
colonialidade, saberes subalternos e pensamento limiar. Belo Horizonte: Editora UFMG, 2003. p. 239-294.

PAZ, Octavio. Hijos de la Malinche. In: El laberinto de la soledad. Editora Fondo de Cultura Económica de España, SL, 1998. p. 27-36.

SANTOS, Dominique Vieira Coelho. Acerca do conceito de representação. Revista de Teoria da História, Ano 3, no 6, dez/2011 Universidade Federal de Goiás.

Recebido em 31 de maio de 2019.

Aceite em 03 de agosto de 2019. 